results which can only be explained by incomplete dissociation. Apart from the important idea of incomplete dissociation and its careful experimental support, Prof. Davies's other main contribution to electrochemistry was his book, "The Conductivity of Solutions", published in 1929 and in 1933 . His more recent work in the field includes studies of the polyphosphate ions in solution, as examples of ions with high negative charges, and the use of ionexchange resins in electrochemistry. In addition to his personal researches, he has played a major part in building up the Chemistry Department at Aberystwyth to achieve its present reputation as an active centre in physical chemistry.

Prof. A. F. Trotman-Dickenson

Dr. A. F. Trotman-Dickenson, who has been appointed to succeed Prof. Davies, is at present lecturer in chemistry in the University of Edinburgh. In the course of a research career of more than ten years, he has made several important contributions to chemical kinetics, chiefly to the study of elementary reactions in gases. His work with Dr. E. W. R. Steacie at the National Research Council in Canada on the reactions of methyl radicals gave information about the rates with which these radicals abstract hydrogen from a wide range of compounds. Dr. TrotmanDickenson has studied the abstraction, decomposition and disproportionation reactions of many alkyl radicals and has obtained an important body of new information. In collaboration with Dr. J. H. Knox, he has developed competitive methods for obtaining relative rates of reaction of halogen atoms with various alkanes and has extended such methods to the study of oxidation. He has made contributions to the study of the reactions of the methylene radical. In yet another recent series of experiments, Dr. Trotman-Dickenson has determined several carbonmetal bond-strengths by kinetic methods. In addition to his main work on elementary reactions, Dr. Trotman-Dickenson, along with Drs. H. O. Pritchard and R. G. Sowden at Manchester, has made a most important detailed investigation of the effect of added gases on the rate of isomerization of cyclopropane; this gave valuable information about energy transfer to reacting molecules. His book, "Gas Kinetics", published in 1954, is a useful survey of this branch of chemistry, and his recent monograph, "Free Radicals", is a valuable introductory text.

\section{Agricultural Sciences in the Rockefeller Founda- tion : Dr. A. H. Moseman}

Dr. Albert H. Moseman has been appointed director for the agricultural sciences in the Rockefeller Foundation. Dr. Moseman went to the Rockefeller Foundation in 1956 as associate director for the agricultural sciences. Previously he was director of crops research of the Agricultural Research Service of the U.S. Department of Agriculture. He was born in Oakland, Nebraska, received the B.S. and M.S. degrees from the University of Nebraska and the Ph.D. degree in plant breeding and geneties from the University of Minnesota. He served on the mission which helped plan the Point IV programme in agriculture, and was a member of the joint Indo-American team which developed recommendations to the Government of India for improvements in agricultural research and education. The University of Minnesota conferred its Outstanding Achievement Award on Dr. Moseman in 1958.
Biology at Oregon:

Prof. G. Streisinger

Dr. George Streisinger has been appointed associate professor of biology in the Institute of Molecular Biology at the University of Oregon as from September 1. Prof. Streisinger is at present at the Carnegie Institution of Washington, Department of Geneties, Cold Spring Harbor, New York. He took his Ph.D. degree in bacteriology at the University of Illinois, and was a post-doctoral fellow of the National Foundation for Infantile Paralysis at the California Institute of Technology. He spent the year 1957-58 working with Dr. Francis Crick in the Cavendish Laboratory, Cambridge. Dr. Streisinger's principal research interest at present is in the relationship between the structure of a protein (bacteriophage lysozyme) and the structure of the gene which controls its formation.

\section{Experimental Biology at Rehovoth, Israel :}

Prof. J. Berenblum

THE establishment of the Jack Cotton research professorship of experimental biology at the Weizmann Institute of Science, Rehovoth, Israel, will help to consolidate and further the work carried out in the Department of Experimental Biology at the Institute. The first holder of the chair will be Prof. I. Berenblum, who has been in charge of the Department since its inception in 1950. This Department comprises a number of sections in different branches of biology and experimental medicine, several of them connected with cancer research-the field of Prof. Berenblum's own specialization. Prof. Berenblum is a graduate of the University of Leeds, a former Beit Memorial Research Fellow (at the Dunn School of Pathology, University of Oxford), and at one time in charge of the Oxford University Research Centre of the British Empire Cancer Campaign. His field of research has been mainly concerned with the 'two-stage mechanism' of carcinogenesis. The proposed expanded programme of research, aided by the munificent gift of Mr. Jack Cotton, will entail the expansion of the work on the two-stage mechanism of carcinogenesis, with particular emphasis on the biological and biochemical role of urethane in the twostage process, and the extension of the principle to systems other than the skin, including its recently discovered role in leukæmogenesis. The recent addition of further animal buildings, X-ray equipment, and the intended expansion of its biochemical facilities, will further the projected expansion of the research programme.

\section{Amalgamation of the Institute of Physics and the} Physical Society

Thr Institute of Physics and the Physical Society have amalgamated and the new body will be known as "The Institute of Physics and the Physical Society". The first president of the amalgamated body is Sir John Cockeroft, and the four vice-presidents are Dr. J. Topping, Dr. W. H. Taylor, Prof. R. W. Ditchburn and Mr. A. J. Philpot, each responsible to the Council for a defined area of the many activities to be taken over by the new organization from its predecessors. The presidents of the original bodies, Sir George Thomson and Mr. J. A. Ratcliffe, are also members of the new Council. The other officers are Dr. J. Taylor (honorary treasurer) and Dr. C. G. Wynne (honorary secretary).

The Physical Society of London, as it was then called, was founded in 1874, and on the initiative of 